\title{
The Effects of Microwave-Assisted Pretreatment and Cofermentation on Bioethanol Production from Elephant Grass
}

\author{
Sefrinus Maria Dolfi Kolo $\mathbb{D D}^{1}$ Deana Wahyuningrum $\mathbb{D D}^{2},{ }^{2}$ and Rukman Hertadi ${ }^{3}{ }^{3}$ \\ ${ }^{1}$ Department of Chemistry, Faculty of Science and Technology, Timor University, Kupang Timor, East Nusa Tenggara, Indonesia \\ ${ }^{2}$ Organic Chemistry Research Division, Faculty of Mathematics and Natural Sciences, Bandung Institute of Technology, \\ Bandung 40132, West Java, Indonesia \\ ${ }^{3}$ Biochemistry Research Division, Faculty of Mathematics and Natural Sciences, Bandung Institute of Technology, \\ Bandung 40132, West Java, Indonesia
}

Correspondence should be addressed to Rukman Hertadi; rukman@chem.itb.ac.id

Received 18 July 2019; Revised 4 July 2020; Accepted 22 October 2020; Published 10 November 2020

Academic Editor: Giuseppe Comi

Copyright (c) 2020 Sefrinus Maria Dolfi Kolo et al. This is an open access article distributed under the Creative Commons Attribution License, which permits unrestricted use, distribution, and reproduction in any medium, provided the original work is properly cited.

\begin{abstract}
The process of acid hydrolysis using conventional methods at high concentrations results in products having lower yields, and it needs a longer time of process; therefore, it becomes less effective. In this study, we analyzed the effects of microwave-assisted pretreatment and cofermentation on bioethanol production from elephant grass (Pennisetum purpureum). We used a combination of delignification techniques and acid hydrolysis by employing a microwave-assisted pretreatment method on elephant grass (Pennisetum purpureum) as a lignocellulosic material. This was followed by cofermentation with Saccharomyces cerevisiae ITB-R89 and Pichia stipitis ITB-R58 to produce bioethanol. The optimal sugar mixtures (fructose and xylose) of the hydrolysis product were subsequently converted into bioethanol by cofermentation with $S$. cerevisiae ITB-R89 and $P$. stipitis ITB-R58, carried out with varying concentrations of inoculum for 5 days $(48 \mathrm{~h})$ at $30^{\circ} \mathrm{C}$ and $\mathrm{pH} 4.5$. The high-power liquid chromatographic analysis revealed that the optimal inoculum concentration capable of converting $76.15 \%$ of the sugar mixture substrate (glucose and xylose) to $10.79 \mathrm{~g} / \mathrm{L}(34.74 \%$ yield) of bioethanol was $10 \%(\mathrm{v} / \mathrm{v})$. The optimal rate of ethanol production was $0.45 \mathrm{~g} / \mathrm{L} / \mathrm{d}$, corresponding to a fermentation efficiency of $69.48 \%$.
\end{abstract}

\section{Introduction}

In Indonesia, the national consumption of fossil fuels has been increasing annually. This increase is attributed to population growth, transportation use increase, and industrial activity upsurge. In addition, high fuel requirements are exacerbated by a decline in oil production capacity. Therefore, there is an immediate need to switch from using fossil fuels to biofuels [1].

Importantly, waste or nonfood materials with high biomass content, such as straw, grass, wood, and empty fruit bunches of palm trees, can be converted to bioethanol without affecting food supplies. One such nonfood material with a high biomass content is elephant grass (Pennisetum purpureum), which is abundantly found in tropical countries such as Indonesia. Biomass of elephant grass is mostly in the form of cellulose (31.5\%), hemicellulose (34.3\%), and lignin (34.2\%) [2]. The high content of cellulose and hemicellulose in elephant grass makes it an excellent source as feedstock for bioethanol production.

Typically, cellulose and hemicellulose from elephant grass can be obtained within $1-2 \mathrm{~h}$ by delignification process involving incubation in an alkaline solution at high temperatures (above $120^{\circ} \mathrm{C}$ ) [3]. Next, the obtained cellulose and hemicellulose are converted to simple carbohydrates (Dxylose, D-glucose, D-mannose, D-galactose, and L-mannose) by acid hydrolysis, in which the $\beta$-(1,4)-glycosidic bond is broken by a strong acid, such as $\mathrm{H}_{2} \mathrm{SO}_{4}$ or $\mathrm{HCl}$. However, this process of delignification and hydrolysis is not without limitations. When the alkaline delignification process occurs 
over a long duration, it may cause conversion of other lignocellulose components into secondary compounds such as xylitol, succinic acid, lactic acid, furfural, hydroxymethylfurfural, acetic acid, and glycerol, all of which can act as inhibitors in the next phase of hydrolysis [4]. In addition, the process of acid hydrolysis using conventional methods at high concentrations results in products having lower yields within a long period of time; therefore, the process becomes less effective. Furthermore, the residual acid waste can have a negative impact on the environment.

To overcome the aforementioned inefficiencies and environmental concerns of using conventional methods, a novel alternative method is to use a microwave oven to delignify and hydrolyze lignocellulose. In this process, the concentration of the base solution used is lower than that used in the conventional (reflux) method, with lower temperature conditions and shorter reaction times. Wang et al. demonstrated that the use of the microwave-assisted delignification process (base-catalyzed process) was more effective in increasing the release of lignin from biomass than conventional methods. They were also able to decompose up to $90 \%$ lignin in biomass samples by using an ionic liquid (1-ethyl-3-methylimidazolium acetate) as a solvent, which was more effective than the conventional delignification process, which released only $70 \%-80 \%$ lignin from lignocellulose components following refluxing the biomass for $16 \mathrm{~h} \mathrm{[4].}$

The microwave-assisted method has also been applied in the acid hydrolysis process of cellulose and hemicellulose, in which the rate of hydrolysis of starch to glucose increased 50-100 times as compared to the conventional heating method [5]. Because the concentration of acid used is also lower, this process requires shorter production time and is more environmental friendly and economical.

Fermentation processes by Saccharomyces cerevisiae and Zymomonas mobilis to produce ethanol typically use only glucose, not pentose sugars, as raw material, because either yeast cannot metabolize pentose sugars. However, some yeasts such as Pichia stipitis metabolize not only glucose but also other pentose sugars, such as xylose, to produce ethanol. A limitation of P. stipitis, however, is that its level of tolerance to ethanol is low, making cofermentation methods crucial. Cofermentation is a process of coculture, usually, $S$. cerevisiae with $P$. stipitis, wherein hexose and pentose sugars are gradually metabolized to produce ethanol [6]. In this study, we analyzed the effects of microwave-assisted pretreatment and cofermentation on bioethanol production from elephant grass.

\section{Methods}

2.1. Chemicals. DNS reagents $\left(\mathrm{Na}_{211} \mathrm{~S}_{2} \mathrm{O}_{3}, \mathrm{NaOH}, 3,5\right.$-dinitrosalicylic acid, and sodium-potassium tartrate) and glucose, xylose, $\mathrm{H}_{2} \mathrm{SO}_{4}, \mathrm{NaOH}$, and $\mathrm{HCl}$ were purchased from
Merck. All the chemicals used were of analytic grade and were used without further purification. All aqueous solutions were prepared and dissolved in distilled water.

2.2. Strains and Culture Media. Bioethanol was produced from elephant grass by delignification and dilute acid hydrolysis using a microwave-assisted pretreatment method, followed by cofermentation using two strains of yeasts. P. stipitis ITB-R58 and S. cerevisiae ITB-R89 strains were obtained from the Microbiology Laboratory, Chemical Engineering Department, Institut Teknologi Bandung. Agar plates $(10.0 \mathrm{~g} / \mathrm{L}$ yeast extract, $20 \mathrm{~g} / \mathrm{L}$ peptone, $20.0 \mathrm{~g} / \mathrm{L}$ glucose, and $25.0 \mathrm{~g} / \mathrm{L}$ bacterial agar) and an inoculum medium $(5.0 \mathrm{~g} / \mathrm{L}$ yeast extract, $5.0 \mathrm{~g} / \mathrm{L}$ peptone, with $20.0 \mathrm{~g} / \mathrm{L}$ mixtures of xylose and glucose as a carbon source) were used for maintaining the cultures. The fermentation medium $(5.0 \mathrm{~g} / \mathrm{L}$ yeast extract, $5.0 \mathrm{~g} / \mathrm{L}$ peptone, $5.0 \mathrm{~g} / \mathrm{L} \quad \mathrm{KH}_{2} \mathrm{PO}_{4}, 0.4 \mathrm{~g} / \mathrm{L}$ $\mathrm{MgSO}_{4} \cdot 7 \mathrm{H}_{2} \mathrm{O}, 0.5 \mathrm{~g} / \mathrm{L} \mathrm{NH} \mathrm{SO}_{4}, 18.71 \mathrm{~g} / \mathrm{L}$ glucose hydrolysate, and $13.61 \mathrm{~g} / \mathrm{L}$ xylose hydrolysate) was used to produce bioethanol.

2.3. Cultivation Conditions. The growth curves of $P$. stipitis ITB-R58 and S. cerevisiae ITB-R89 strains were determined according to the method of Arnata [7]. A single colony of each species was grown on a starter medium $(0.5 \%(\mathrm{w} / \mathrm{v})$ peptone, $1.0 \%(\mathrm{w} / \mathrm{v})$ yeast extract, and $2 \%$ $(\mathrm{w} / \mathrm{v})$ glucose and xylose), followed by incubation at $37^{\circ} \mathrm{C}$ with vigorous shaking $(150 \mathrm{rpm})$ overnight. Before the growth curve experiment, $0.1 \%$ of the culture was transferred to a production medium and incubated under the same conditions. The growth of both yeast cultures was monitored every day by measuring their optical density (OD) at $600 \mathrm{~nm}$.

2.4. Sample Preparation, Delignification, and Dilute Acid Hydrolysis of Elephant Grass Using a Microwave-Assisted Pretreatment Method. Initially, the lignocellulose content of elephant grass was determined according to Surajit's method [8]. An amount of 1 gram of sample in $150 \mathrm{~mL} \mathrm{H}_{2} \mathrm{O}$ was refluxed for 2 hours at $100^{\circ} \mathrm{C}$. The residual sample that had been dried was refluxed for 2 hours with $150 \mathrm{~mL} 0.5 \mathrm{M} \mathrm{H}_{2} \mathrm{SO}_{4}$ at $100^{\circ} \mathrm{C}$. The residue of the sample that has been dried was immersed in $10 \mathrm{~mL} \mathrm{72 \%}$ (v/v) $\mathrm{H}_{2} \mathrm{SO}_{4}$ solution at room temperature for 4 hours, then diluted to $0.5 \mathrm{M} \mathrm{H}_{2} \mathrm{SO}_{4}$, and subsequently refluxed at $100^{\circ} \mathrm{C}$ for 2 hours, then dried. The residue was filtered and washed with demineralized water to neutral. The residue was then dried in an oven at a temperature of $105^{\circ} \mathrm{C}$ until the weight was constant and subsequently weighed (weight $d$ ). Afterward, the residue was fumed to ash and weighed (weight $e$ ). The composition of the lignocellulosic 
components of the elephant grass sample was determined using the following calculation [8]:

$$
\begin{gathered}
\text { hemicellulose (\%): } \frac{b-c}{a} \times 100 \%, \\
\text { cellulose (\%): } \frac{c-d}{a} \times 100 \%, \\
\text { lignin (\%): } \frac{d-e}{a} \times 100 \%, \\
\text { ash content: } \frac{e}{a} \times 100 \%,
\end{gathered}
$$

with $a$ is the initial weight of the dried powder of elephant grass samples; $b$ is the weight of the dried sample residue after refluxed with hot water; $c$ is the weight of sample residues after refluxed with $0.5 \mathrm{M} \mathrm{H}_{2} \mathrm{SO}_{4}$; $d$ is the weight of sample residues after being treated with $72 \%(\mathrm{v} / \mathrm{v})$ $\mathrm{H}_{2} \mathrm{SO}_{4}$ solution; and $e$ is the weight of ash from sample residues.

Elephant grass was washed and dried overnight before cutting them into $1 \mathrm{~cm}$ long pieces. Subsequently, the grass was blended and dried in an oven for $4 \mathrm{~h}$ at $60^{\circ} \mathrm{C}$. The grass powder was then sieved to obtain a 100 -mesh powder. The powder was characterized using a scanning electron microscope (SEM) (JSM-6510LA).

The delignification method was performed according to that proposed by Chen et al., with slight modifications [5], particularly in this study using the microwave-assisted delignification process. A total of $20 \mathrm{~g}$ of the sieved powder was placed in a $500 \mathrm{~mL}$ glass beaker and suspended in $300 \mathrm{~mL}$ of a $2 \%(\mathrm{w} / \mathrm{v}) \mathrm{NaOH}$ solution. The suspension was placed in a microwave reactor SINEO MAS II, followed by heating under a $400 \mathrm{~W}$ microwave irradiation power for $30 \mathrm{~min}$ at $90^{\circ} \mathrm{C}$. The heated mixtures were subsequently filtered and washed with hot water and neutralized with an acid. The resulting powder was dried, and the surface morphology of the powder was analyzed using an SEM.

Subsequently, the elephant grass powder from the delignification process $( \pm 10 \mathrm{~g})$ was hydrolyzed by $\mathrm{H}_{2} \mathrm{SO}_{4}$ solution $(250 \mathrm{~mL})$ and irradiated in the SINEO MAS II microwave reactor at an irradiation power of $400 \mathrm{~W}$ at $95^{\circ} \mathrm{C}$ [9]. The optimization conditions of the microwave-assisted hydrolysis of delignified elephant grass powder in this study were performed as shown in Table 1 .

The hydrolyzed product was filtered and subsequently neutralized. The solid product was further characterized by scanning electron microscopy for surface topology. The reducing sugar content of the solution was measured with a DNS method using a Biochrom Libra S70 UV-Vis Spectrophotometer, and the xylose content was determined by high-performance liquid chromatography (HPLC) using an $\mathrm{HP}$ Aminex $87 \mathrm{H}$ column (at a flow rate of $0.6-0.8 \mathrm{~mL} / \mathrm{min}$, with a column temperature of $75^{\circ} \mathrm{C}$ ).

2.5. Cofermentation Process for Bioethanol Production. Cofermentation of the sugar mixtures was performed according to the procedure of Yadav et al., with slight modifications, using $P$. stipitis ITB-R58 and $S$. cerevisiae ITB-R89 cultures [10]. The fermentation medium was added to the hydrolysate solution, followed by autoclaving for $15 \mathrm{~min}$ at $120^{\circ} \mathrm{C}$. The yeast cultures were transferred to the sterile fermentation medium and incubated anaerobically at $30^{\circ} \mathrm{C}$. The $\mathrm{pH}$ of the medium was adjusted to 4.5 by adding $\mathrm{NaOH}$ or $2.0 \mathrm{M} \mathrm{HCl}$ solution. To evaluate the inoculum concentration on bioethanol production, cell concentrations were varied (i.e., $5.0 \% ; 10.0 \%$, and $20.0 \%(\mathrm{v} / \mathrm{v})$ ) during the cofermentation process. Residual glucose, xylose, and acetic acid were determined by HPLC [6]. The data were recorded every 5 days.

\section{Results and Discussion}

3.1. Morphology of Elephant Grass before and after Treatment. Elephant grass, as the lignocellulosic biomass used in this study, contains cellulose, hemicellulose, and lignin as its primary components [11]. However, its composition varies substantially, depending on the variety, climate, and soil fertility. Understanding its chemical composition is important for developing effective pretreatment methods to deconstruct its rigid structure and select the appropriate microorganisms to convert sugars into bioethanol. Hence, the structural carbohydrate contents of the grass were determined before and after the treatments both by monitoring the surface morphology of the grass and by measuring the chemical contents of the grass.

The surface morphology of the grass is shown in Figure 1. The results revealed that the surface morphology of the grass powder was compact and rigid before delignification and acid hydrolysis (Figure 1(a)). The treatment also removes acetyl and other acidic substitutions on hemicelluloses that protect cellulose. The scanning electron microscopy results revealed that the grass powder was broken after delignification (Figure 1(b)). The surface morphology of the grass powder after delignification and acid hydrolysis treatment underwent more significant damage, indicating that both treatments were successful in degrading the lignocellulosic parts of the grass powder (Figure 1(c)).

A delignification process using $\mathrm{NaOH}$ combined with microwave-assisted pretreatment technique helped degrade and release lignin from cellulose or hemicellulose materials. This is because lignin is not a sugar-based polymer and cannot be used as feedstock for bioethanol production via microbial fermentation as it inhibits microbial growth and fermentation process [4]. In addition, the treatment removes acetyl and other acidic substitutions on hemicelluloses that protect cellulose from attack by cellulases. The scanning electron microscopy results revealed that the grass powder was broken after delignification, as is shown in Figure 1(b). Furthermore, acid hydrolysis was required after delignification to degrade the $\beta$-1,4-glycosidic bond of linear glucan chains of cellulose or $\beta-1,4-D$-pyranosyl linkage of heterogeneous polysaccharides of hemicellulose to monomer sugars, such as glucose, xylose, galactose, arabinose, and mannose. 
TABLE 1: The optimization conditions of the microwave-assisted hydrolysis of delignified elephant grass powder with acid catalyst using the SINEO MAS II microwave reactor.

\begin{tabular}{lcccc}
\hline Treatment & The concentration of $\mathrm{H}_{2} \mathrm{SO}_{4}$ in $\%(\mathrm{v} / \mathrm{v})$ & Irradiation power (watt) & Reaction time (minutes) & Temperature $\left({ }^{\circ} \mathrm{C}\right)$ \\
\hline 1 & $0.5 ; 1 ; 2 ; 5 ;$ and 7 & 400 & 30 & 90 \\
2 & 2 & $300 ; 400 ; 500 ; 600 ;$ and 700 & 30 & 90 \\
3 & 2 & 400 & $5 ; 10 ; 20 ; 30 ;$ and 40 & 90 \\
4 & 2 & 400 & 30 & $80 ; 90 ; 95 ; 100$ and 110 \\
\hline
\end{tabular}
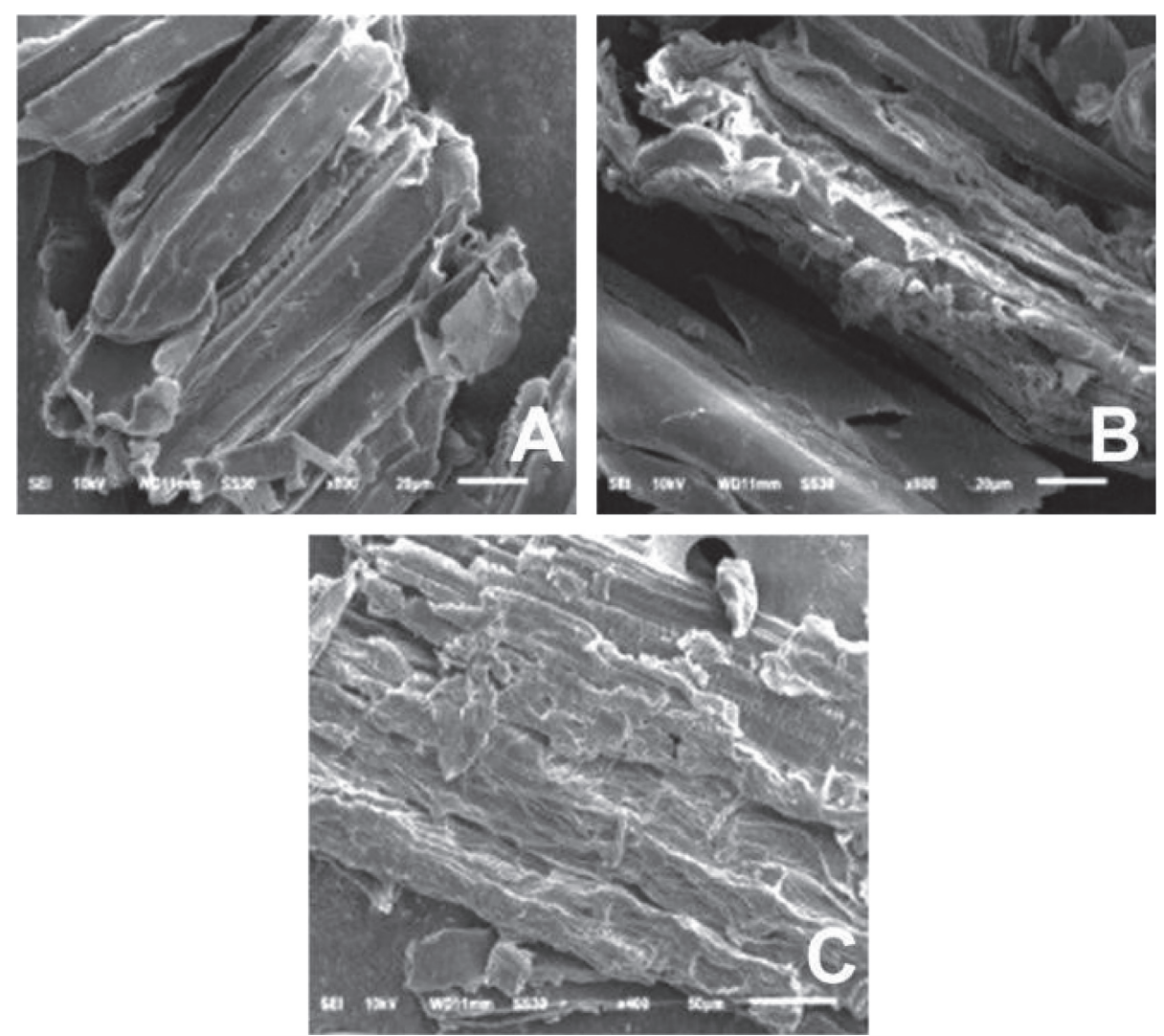

Figure 1: Morphology of the elephant grass powder: (a) before treatment; (b) after delignification process; and (c) after the delignification process followed by acid hydrolysis.

3.2. Chemical Content of Grass Powder. The results demonstrated that the cellulose content after alkaline delignification using the microwave-assisted pretreatment technique was higher $(43.6 \%)$ than the usual alkaline delignification technique $(37.1 \%)$ (Table 2 ).

Our findings demonstrated that the cellulose content after alkaline delignification using microwave-assisted pretreatment technique was higher $(43.6 \%)$ than that obtained using the usual alkaline delignification technique (37.1\%), as well as alkaline delignification combined with heat $(31.2 \%$ as studied by Eliana et al. [3]). The high levels of cellulose content obtained in this study indicated that the alkaline delignification process with microwave-assisted pretreatment technique successfully damaged the structural linkages between lignin and carbohydrates and released the free cellulose into solution. However, the cellulose and hemicellulose contents were decreased after acid hydrolysis, as this process will also break down the glycosidic linkage of cellulose or $\delta$-1,4-D-pyranosyl linkage of hemicellulose, producing its monosaccharides. Yadaf et al. reported that conventional acid hydrolysis of $100.0 \mathrm{~g}$ of elephant grass yielded $48.06 \mathrm{~g}$ of cellulose [10]. Meanwhile, in our study, $100.0 \mathrm{~g}$ of elephant grass resulted in $52.6 \mathrm{~g}$ of cellulose. Björling and Lindman used the combination of electron beam irradiation and alkaline delignification for pretreatment of corn stalks [12]. They reported that the glucose yield was $20 \%$ in untreated samples compared to $43 \%$ in samples treated with electron beam irradiation and $\mathrm{NaOH}$ delignification. Jeffries and Jin also reported that the hydrolysis rate of starch to glucose increased 100 times by using microwave irradiation [13].

All of the above results suggest that the microwaveassisted pretreatment techniques combined with alkaline delignification and acid hydrolysis methods are capable of degrading cellulose effectively and efficiently with a shorter reaction time, as well as substantially reducing the lignin 
TABLE 2: The lignocellulose content of the elephant grass powder ${ }^{\mathrm{a}}$.

\begin{tabular}{|c|c|c|c|c|}
\hline Process & $\begin{array}{l}\text { Cellulose } \\
(\%)\end{array}$ & $\begin{array}{l}\text { Hemicellulose } \\
(\%)\end{array}$ & $\begin{array}{l}\text { Lignin } \\
(\%)\end{array}$ & $\begin{array}{l}\text { Ash } \\
(\%)\end{array}$ \\
\hline No treatment & 29.9 & 20.2 & 21.1 & 7.2 \\
\hline After alkaline delignification & 37.1 & 19.5 & 24.3 & 17.4 \\
\hline After alkaline delignification + microwave-assisted pretreatment techniques & 43.6 & 21.1 & 10.8 & 10.7 \\
\hline $\begin{array}{l}\text { After alkaline delignification and acid hydrolysis (both combined with microwave- } \\
\text { assisted pretreatment techniques) }\end{array}$ & 12.8 & 12.4 & 5.5 & 24.1 \\
\hline
\end{tabular}

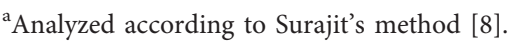

content and the side products, compared to conventional methods [5].

Fermentation of lignocellulosic hydrolysates was more difficult than the well-established process of bioethanol production (e.g., from sugar-cane juice), because the hydrolysates contain a broader range of inhibitory compounds. Inhibitor composition and concentration depend on not only the type of lignocellulosic materials but also the chemistry and nature of the pretreatment and hydrolysis processes [14]. Moreover, the hydrolysates of hemicelluloses contain both hexoses and pentoses, whereas xylose usually is the dominant sugar in the hydrolysates from hardwood hemicelluloses [15]. Therefore, the fermenting microorganisms that were used in our experiment should be able to produce bioethanol from the hydrolysates (including pentoses) with a high yield and productivity as well as be safe for humans.

\subsection{The Concentration of the Reducing Sugar after Delignification Process}

3.3.1 Hydrolysis of Elephant Grass Powder without Microwave Assistance. The effect of time-period on alkaline delignification and the optimal sulfuric acid concentration for acid hydrolysis was evaluated using the DNS method to determine the concentration of reducing sugars produced from the aforementioned treatments. All the experiments were conducted without microwave-assisted pretreatment. Four conditions for each treatment were tested: $1.5,2.0,2.5$, and $3.0 \mathrm{~h}$ for delignification time, as well as $0.5 \%, 2.0 \%, 5.0 \%$, and $7.0 \%(\mathrm{v} / \mathrm{v})$ for sulfuric acid concentration. The results are presented in Figure 2, which are based on two time experiments represented as the mean concentration of reducing sugar (in $g / L$ ) produced (Table 3).

It was observed that $2.5 \mathrm{~h}$ for the delignification process and $7.0 \%(\mathrm{v} / \mathrm{v})$ of sulfuric acid concentration were the best conditions for producing $9.41 \mathrm{~g} / \mathrm{L}$ of the reducing sugar from elephant grass powder. However, this result is still lower than the previous result by Eliana et al., who conducted the usual delignification method and enzymatic hydrolysis of the cellulose fraction of the elephant grass and produced $34.4 \mathrm{~g} / \mathrm{L}$ of the reducing sugar [3]. Therefore, in this study, the delignification process of the elephant grass powder sample was modified by following the acid hydrolysis using microwave irradiation heating.

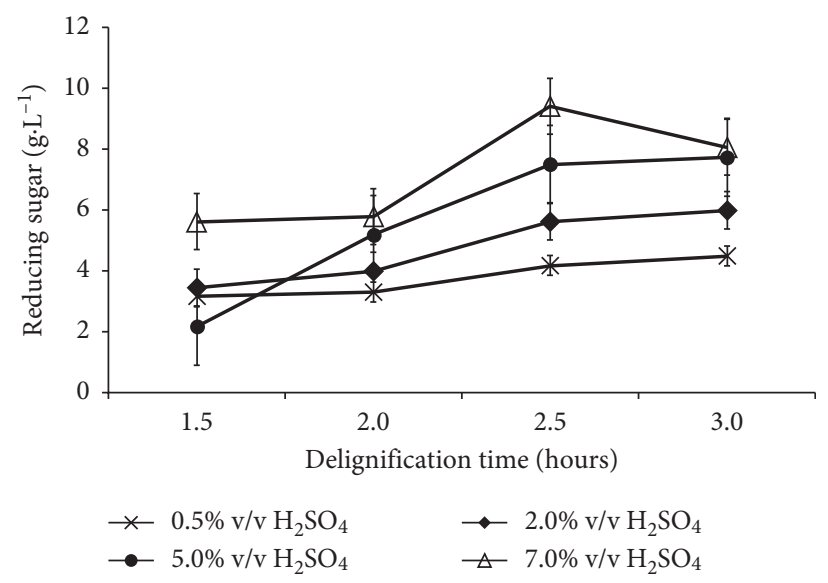

FIGURE 2: The concentration of the reducing sugar $(\mathrm{g} / \mathrm{L})$ produced from alkaline delignification of elephant grass powder followed by acid hydrolysis at various concentrations of sulfuric acid.

3.3.2 Hydrolysis of Elephant Grass Powder through Microwave Assistance. In this study, to obtain higher yields of glucose/reducing sugar, we modified the pretreatment process by including the microwave-assisted pretreatment technique, which used microwave irradiation to increase the reaction efficiency. Results of the delignification and hydrolysis of the elephant grass powder by using microwave irradiation heating are presented in Table 4. The power of microwave irradiation seemed to affect the amount of reducing sugars significantly. The results revealed that the concentration of reducing sugars was decreased with the increase of temperature and the microwave irradiation power (Table 4).

Based on the results of hydrolysis in Table 2 shows the increased concentration of sulfuric acid used in the hydrolysis process, the resulting reducing sugar concentration increased. However, it decreased at 5\% (v/v) sulfuric acid concentration, 40 minutes of hydrolysis time, the temperature of $95^{\circ} \mathrm{C}$, and irradiation power of $500 \mathrm{~W}$. This condition was due to some products being converted into secondary compounds such as furfural and hydroxymethylfurfural (HMF) [16]. The most optimal condition for the acid hydrolysis of elephant grass combined with microwave-assisted pretreatment technique was at $2 \%(\mathrm{v} / \mathrm{v})$ sulfuric acid concentration with $400 \mathrm{~W}$ irradiation power for $30 \mathrm{~min}$ at $95^{\circ} \mathrm{C}$, which produced $26.63 \mathrm{~g} / \mathrm{L}$ of the reducing sugar, corresponding to a hydrolytic efficiency of $66.57 \%$. This result is higher than the delignification treatment 
TABLE 3: The effect of delignification time and $\mathrm{H}_{2} \mathrm{SO}_{4}$ concentration on the average glucose concentration produced without microwaveassisted pretreatment.

\begin{tabular}{lccccccc}
\hline \multirow{2}{*}{ Concentration of $\mathrm{H}_{2} \mathrm{SO}_{4}$ (in \% (v/v) } & \multicolumn{9}{c}{ Delignification time (hours) } & \multirow{2}{*}{ The average reducing sugar $\left(\mathrm{g} \cdot \mathrm{L}^{-1}\right.$ ) } & \multirow{2}{*}{ Standard deviation } \\
& 1.5 & 2.0 & 2.5 & 3.0 & 3.78 & 0.65 \\
0.5 & 3.15 & 3.31 & 4.17 & 4.49 & 4.77 & 1.24 \\
2.0 & 3.45 & 3.99 & 5.65 & 5.99 & 5.63 & 2.59 \\
5.0 & 2.15 & 5.17 & 7.49 & 7.73 & 7.21 & 1.84 \\
7.0 & 5.61 & 5.79 & 9.41 & 8.05 & \\
\hline
\end{tabular}

TABLE 4: The reducing sugar data produced from the delignification process of elephant grass powder followed by acid hydrolysis using microwave irradiation heating.

\begin{tabular}{|c|c|c|c|c|c|c|c|}
\hline $\mathrm{H}_{2} \mathrm{SO}_{4}(\% \mathrm{v} / \mathrm{v})$ & RS (g/L) & IP (W) & RS (g/L) & RT (min) & RS (g/L) & Temp $\left({ }^{\circ} \mathrm{C}\right)$ & $\mathrm{RS}(\mathrm{g} / \mathrm{L})$ \\
\hline 0.5 & 16.33 & 300 & 14.11 & 5 & 5.61 & 80 & 8.39 \\
\hline 1 & 18.15 & 400 & 25.10 & 10 & 13.99 & 90 & 25.11 \\
\hline 2 & 25.11 & 500 & 19.07 & 20 & 18.65 & 95 & 26.63 \\
\hline 5 & 26.05 & 600 & 16.32 & 30 & 25.11 & 100 & 18.61 \\
\hline 7 & 23.07 & 700 & 14.50 & 40 & 19.63 & 110 & 16.03 \\
\hline
\end{tabular}

Abbreviations: $\mathrm{H}_{2} \mathrm{SO}_{4}$, sulfuric acid; RS, reducing sugar; IP, irradiation power; RT, reaction time; Temp, temperature. Variation in $\mathrm{H}_{2} \mathrm{SO}_{4}$ concentrations of each parameter was carried out without repetition.

without a microwave, which is only $9.41 \mathrm{~g} / \mathrm{L}$ with hydrolysis efficiency of $23.54 \%$ [3]. The reducing sugar concentration was increased by $45.05 \%$ compared to the one without microwave-assisted pretreatment. This optimal condition was also more effective than that in the previous work of Chen et al., who used $0.5 \%(\mathrm{v} / \mathrm{v})$ sulfuric acid concentration with $900 \mathrm{~W}$ microwave irradiation power for $60 \mathrm{~min}$ at $121^{\circ} \mathrm{C}$, producing $11.9 \mathrm{~g} / \mathrm{L}$ of the reducing sugar [5].

Our findings demonstrated that the cellulose content after alkaline delignification using microwave-assisted pretreatment technique was higher $(43.6 \%)$ than that obtained using the usual alkaline delignification technique (37.1\%), as well as alkaline delignification combined with heat $(31.2 \%$ as studied by Eliana et al. [3]). The high levels of cellulose content obtained in this study indicated that the alkaline delignification process with microwave-assisted pretreatment technique successfully damaged the structural linkages between lignin and carbohydrates and released the free cellulose into solution. However, the cellulose and hemicellulose contents were decreased after acid hydrolysis, as this process will also break down the glycosidic linkage of cellulose or $\delta$-1,4-D-pyranosyl linkage of hemicellulose, producing its monosaccharides. Yadav et al. reported that conventional acid hydrolysis of $100.0 \mathrm{~g}$ of elephant grass yielded $48.06 \mathrm{~g}$ of cellulose [10]. Meanwhile, in our study, $100.0 \mathrm{~g}$ of elephant grass resulted in $52.6 \mathrm{~g}$ of cellulose. Björling and Lindman used the combination of electron beam irradiation and alkaline delignification for pretreatment of corn stalks [12]. They reported that the glucose yield was $20 \%$ in untreated samples compared to $43 \%$ in samples treated with electron beam irradiation and $\mathrm{NaOH}$ delignification. Jeffries and Jin also reported that the hydrolysis rate of starch to glucose increased 100 times by using microwave irradiation [13]. All of the above results suggest that the microwave-assisted pretreatment techniques combined with alkaline delignification and acid hydrolysis methods are capable of degrading cellulose effectively and efficiently with shorter reaction time, as well as substantially reducing the lignin content and the side products, compared to conventional methods [5].

3.4. Growth of Cultures. To determine the inoculation time of yeast, the cultivation of yeast cells was evaluated every day (Figure 3). The cell cultures were monitored, and the data were recorded daily for changes in cell numbers by determining the OD of each inoculum. S. cerevisiae required $12 \mathrm{~h}$ to adapt to the medium, to achieve an optimum OD of 0.706 at $48 \mathrm{~h}$. After hour 60, S. cerevisiae entered the dead phase. Meanwhile, the cultivation of $P$. stipitis culture resulted in a slower increase in cell density. The exponential growth of P. stipitis started at hour 24 and lasted until hour 66, with a maximum OD of 0.682 at hour 60 . The cells then entered into the dead phase at hour 84 . These results suggest that the $P$. stipitis was inserted $12 \mathrm{~h}$ faster than $S$. cerevisiae into the elephant grass hydrolysates. Growth curve measurements were performed once without repeating every hour for 4 days.

3.4.1 Effect of Inoculum Concentration. To determine the effect of inoculum concentration on bioethanol production, serial experiments by varying the inoculum concentration of each yeast (i.e., $5 \%, 10 \%$, and $20 \%(\mathrm{v} / \mathrm{v}))$ were conducted during the cofermentation process. The results of HPLC analysis of ethanol and acetic acid contents in products after fermentation were presented in the following figures.

The presence of ethanol and acetic acid in products after fermentation was confirmed by comparing the retention time of ethanol and acetic acid to the standards, as shown in Figures 4 and 5, and ethanol and acetic acid concentrations were calculated using the chromatogram data of HPLC analysis. Subsequent peak area data of each ethanol and acetic acid were inputted into each ethanol and acetic acid standard regression equation derived from the linear plot 


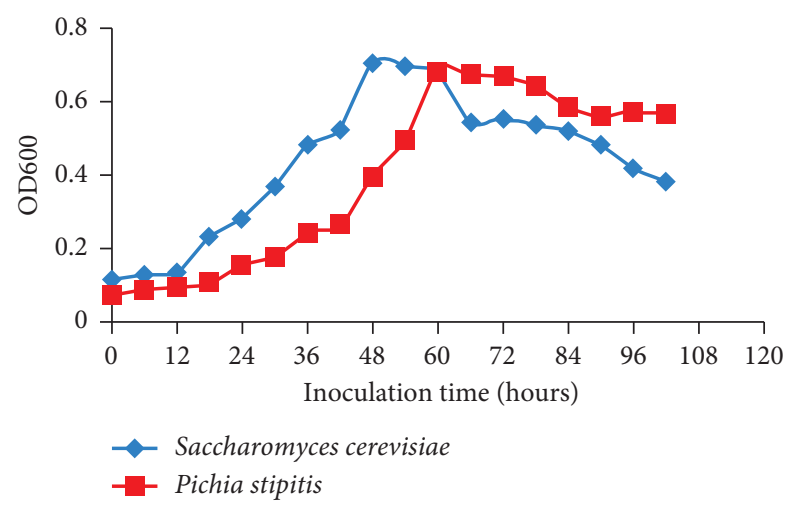

FIgURe 3: The growth curves of Saccharomyces cerevisiae and Pichia stipitis.

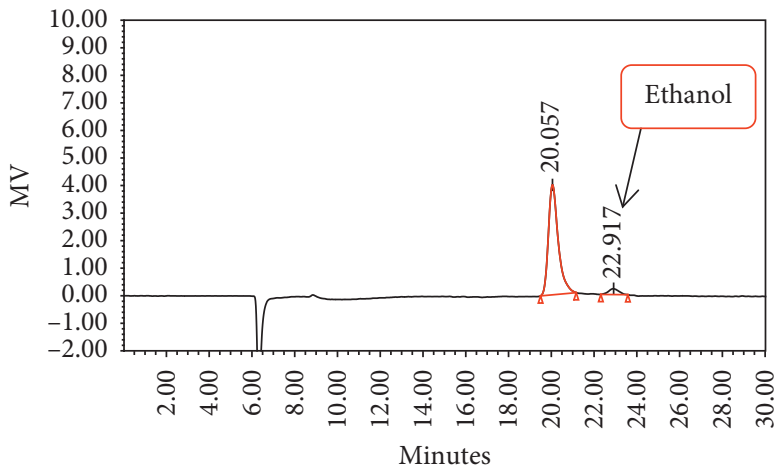

(a)

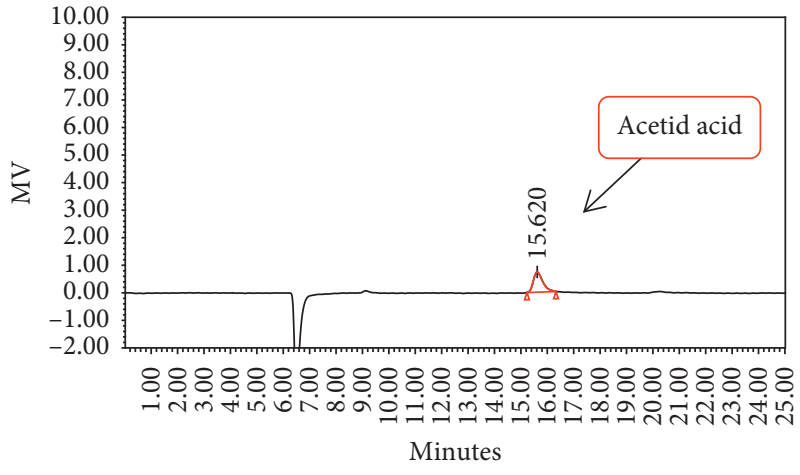

(b)

FIGURE 4: Chromatograms of ethanol and acetic acid standards.

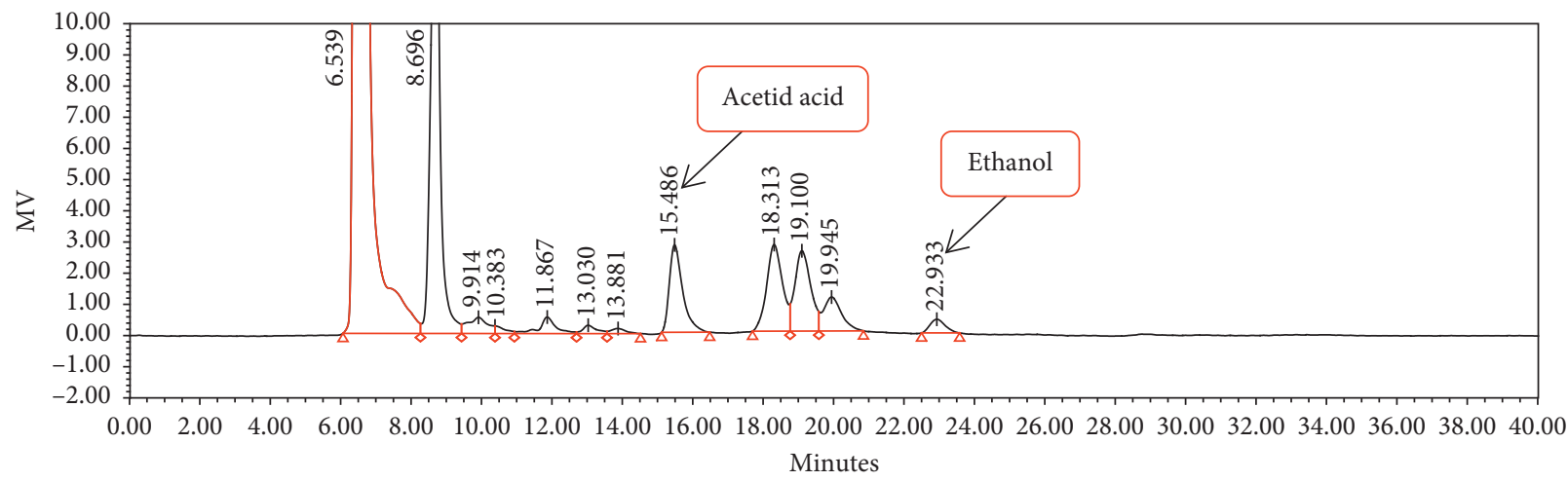

FIGURE 5: Chromatograms of ethanol and acetic acid contents in products after fermentation.

between peak area in chromatogram and concentration of ethanol and acetic acid, as presented in Figures 6 and 7, respectively, to get the ethanol and acetic concentration. The peak area of ethanol on the HPLC analysis chromatogram of the product after fermentation was subsequently inputted into the ethanol standard regression equation as the variable $(y)$ to get the concentration $(x)$, as follows: 


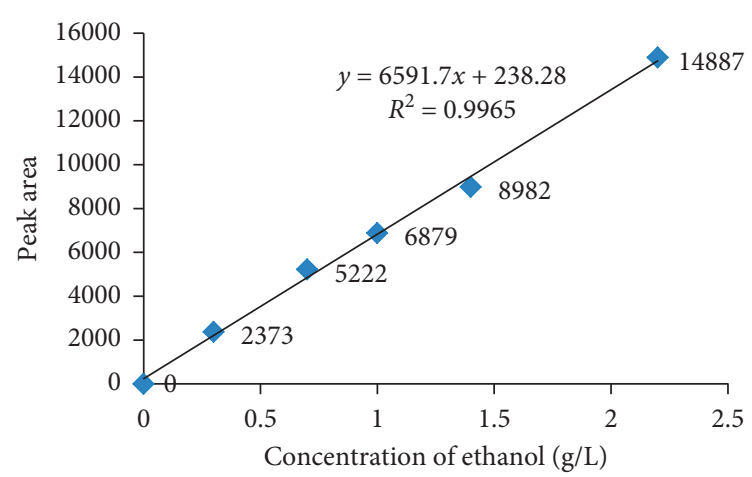

FIGURE 6: The linear plot between peak area in chromatogram and concentration of ethanol.

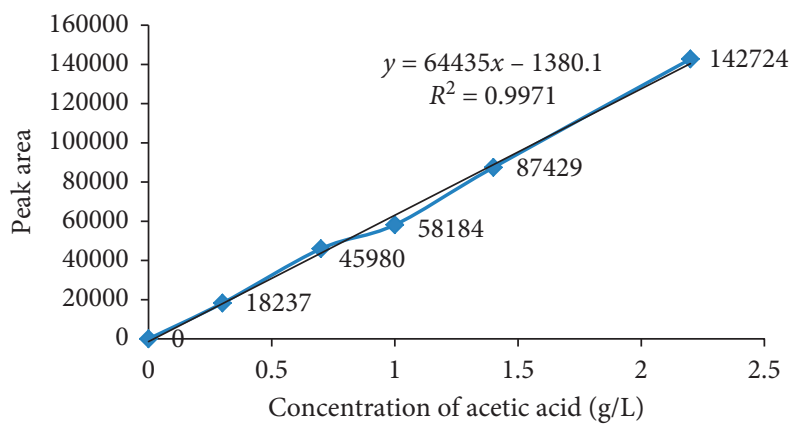

FIgURE 7: The linear plot between peak area in chromatogram and concentration of acetic acid.

$$
\text { ethanol concentration }(x)=\frac{y-b}{a} \text {, }
$$

ethanol concentration $(\mathrm{g} / \mathrm{L})=$ ethanol concentration $(\%) \times \rho \times 10$ (correction factor).

The similar calculation was performed to get the concentration of acetic acid.

The initial concentration of glucose and xylose for 5\%, $10 \%$, and $20 \%(\mathrm{v} / \mathrm{v})$ of inoculum treatments was 16.67 and $6.04 \mathrm{~g} / \mathrm{L} ; 17.43$ and $16.31 \mathrm{~g} / \mathrm{L}$; and 18.45 and $8.45 \mathrm{~g} / \mathrm{L}$, respectively. The initial concentrations of glucose and xylose used were directly obtained from the pretreatment process of elephant grass. The OD, residual glucose and xylose concentration, and bioethanol and acetic acid accumulation were observed every day for 5 days. Both substrate concentrations decreased for all inoculum concentrations during cofermentation, as is shown in Figure 8. Measurement of the optimal concentrations of bioethanol and acetic acid revealed that the $5 \%$ inoculum concentration (Figure $6(\mathrm{a})$ ) produced $5.26 \mathrm{~g} / \mathrm{L}$ bioethanol and $2.24 \mathrm{~g} / \mathrm{L}$ acetic acid at $48 \mathrm{~h}$ of cofermentation, and the concentration of both products decreased after the $72 \mathrm{~h}$ of cofermentation. Under these conditions, the bioethanol yield was $23 \%$, with the highest productivity rate of $0.2 \mathrm{~g} / \mathrm{L}$ per day. The fermentation efficiency reached a rate of $34.41 \%$ and substrate conversion efficiency by $56.38 \%$. Moreover, the $10 \%$ inoculum concentration experiment resulted in an optimal bioethanol concentration at $48 \mathrm{~h}$ of cofermentation
$(10.79 \mathrm{~g} / \mathrm{L}$, Figure $8(\mathrm{~b}))$, with fermentation and conversion substrate efficiencies of $69.48 \%$ and $76.15 \%$, respectively. The bioethanol concentration started decreasing after $72 \mathrm{~h}$ of cofermentation, indicating that the number of substrates was reduced and the yeasts entered into the dead phase after hour 72 . Meanwhile, the $20 \%(\mathrm{v} / \mathrm{v})$ inoculum concentration experiment (Figure 8(c)) revealed slightly different results for the optimal bioethanol concentration, which was $13.31 \mathrm{~g} / \mathrm{L}$ at hour 96 of cofermentation. In addition, the efficiency of fermentation was $66.97 \%$, and the substrate conversion rate reached up to $92.88 \%$. The fermentation process is carried out once for each inoculum for 5 days.

3.4.2 Substrates and Product Parameters Observed during Cofermentation. In this study, the highest bioethanol concentration was $13.31 \mathrm{~g} / \mathrm{L}$, obtained on day 96 with $20 \%$ (v/v) inoculum concentration. However, in terms of the effectiveness and efficiency of the material used, the $10 \%(\mathrm{v} / \mathrm{v})$ inoculum concentration demonstrated better results than other inoculum concentrations (Table 5). The ethanol yield $\left(Y_{\mathrm{p} / \mathrm{s}}\right)$ can be calculated using the following equation: 


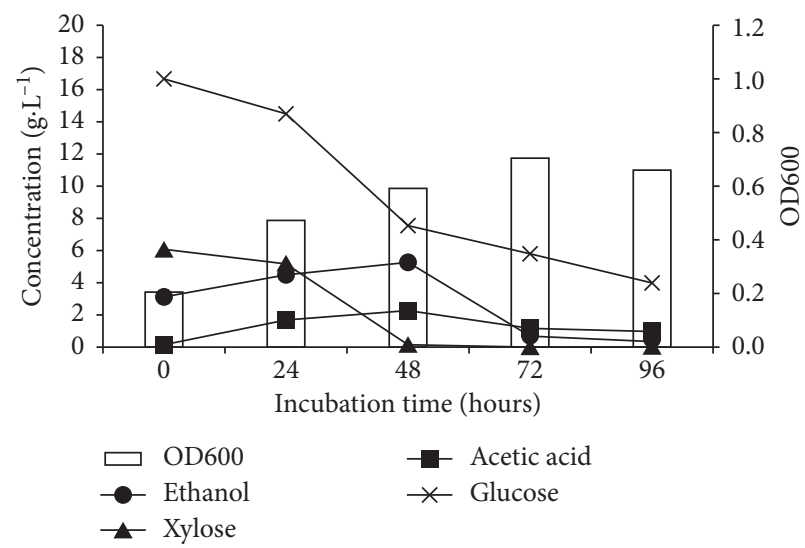

(a)

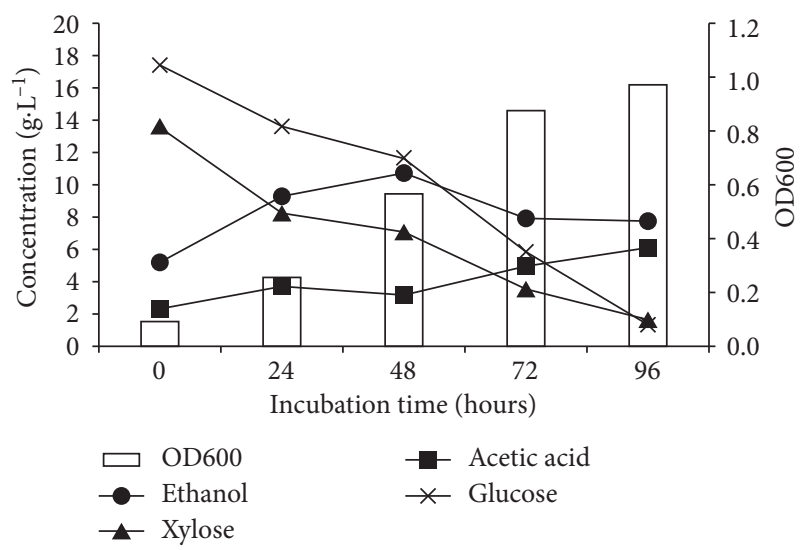

(b)

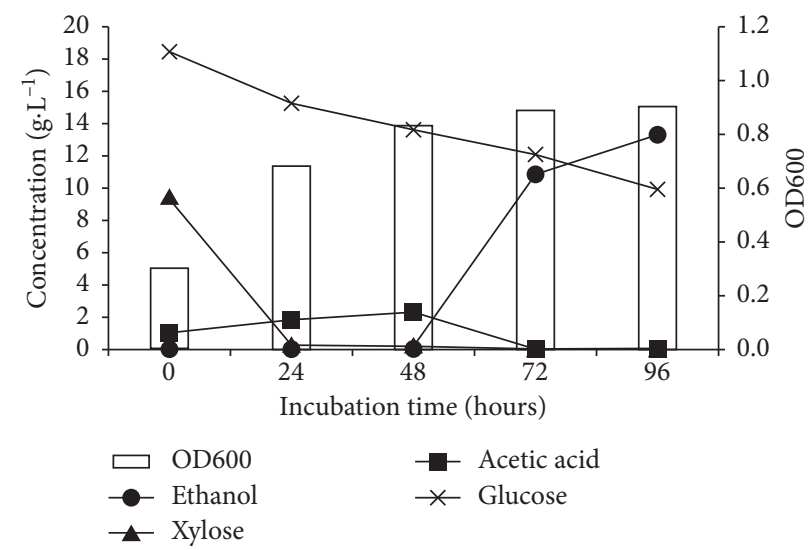

(c)

FigurE 8: The effect of inoculum concentration: (a) 5\%; (b) 10\%; and (c) 20\% (v/v) on bioethanol production.

TABLE 5: Substrates and product parameters observed during cofermentation.

\begin{tabular}{|c|c|c|c|c|}
\hline Time (in h) & $Y_{\mathrm{p} / \mathrm{s}}(\%)$ & $\mathrm{Lp}(\mathrm{g} / \mathrm{L}, \mathrm{h})$ & $\mathrm{EF}(\%)$ & Ks $(\%)$ \\
\hline \multicolumn{5}{|c|}{ Inoculum concentration $5 \%(v / v)$} \\
\hline 0 & 13.55 & 0.13 & 6.77 & 0.00 \\
\hline 24 & 19.63 & 0.19 & 11.37 & 9.35 \\
\hline 48 & 23.15 & 0.22 & 34.41 & 45.32 \\
\hline 72 & 2.80 & 0.03 & 5.48 & 50.86 \\
\hline 96 & 1.33 & 0.01 & 3.83 & 56.38 \\
\hline \multicolumn{5}{|c|}{ Inoculum concentration $10 \%(\mathrm{v} / \mathrm{v})$} \\
\hline 0 & 16.76 & 0.22 & 33.52 & 0.00 \\
\hline 24 & 29.85 & 0.39 & 59.71 & 26.36 \\
\hline 48 & 34.74 & 0.45 & 69.48 & 35.33 \\
\hline 72 & 25.46 & 0.33 & 50.91 & 62.27 \\
\hline 96 & 24.92 & 0.32 & 49.83 & 76.15 \\
\hline \multicolumn{5}{|c|}{ Inoculum concentration $20 \%(\mathrm{v} / \mathrm{v})$} \\
\hline 0 & 0.00 & 0.00 & 0.00 & 0.00 \\
\hline 24 & 0.00 & 0.00 & 0.00 & 59.04 \\
\hline 48 & 0.00 & 0.00 & 0.00 & 66.58 \\
\hline 72 & 38.82 & 0.45 & 44.70 & 76.17 \\
\hline 96 & 47.69 & 0.55 & 66.97 & 92.88 \\
\hline
\end{tabular}

Abbreviations: Ks, total substrate conversion; $Y_{\mathrm{p} / \mathrm{s}}$, ethanol yields (theoretically $=51 \%$ ); $\mathrm{L}_{\mathrm{p}}$, productivity rate of bioethanol per day. 
ethanol yield (\%): $\frac{\text { ethanol concentration }(\mathrm{g} / \mathrm{L})}{\text { reduction sugar concentration }(\mathrm{g} / \mathrm{L})} \times 100$.

Baker's yeast (S. cerevisiae) is the most commonly used microorganism for bioethanol production [13-17]. However, it cannot ferment xylose, as it lacks the genes for xylose reductase $(\mathrm{XR})$ and xylitol dehydrogenase $(\mathrm{XDH})[13,18]$. It was reported that the yeast can tolerate up to $12 \%-18 \%$ of ethanol concentration and about $5 \mathrm{~g} / \mathrm{L}$ undissociated concentration of acetic acid, the most common carbocyclic acid found in the hydrolysates. For a range of temperatures from $4^{\circ} \mathrm{C}$ to $32^{\circ} \mathrm{C}, \mathrm{S}$. cerevisiae was able to ferment glucose, sucrose, and raffinose, exhibiting an optimal activity at $30-34^{\circ} \mathrm{C}$, and not being active at temperatures above $40^{\circ} \mathrm{C}$ at $\mathrm{pH}$ of about 4.5. Ethanol production followed the Embden-Meyerhof-Parnas pathway (EMP) in which glucose was converted to pyruvate, and the pyruvate was converted to acetaldehyde and $\mathrm{CO}_{2}$, catalyzed by pyruvate decarboxylase. The acetaldehyde is then reduced to ethanol by the action of alcohol dehydrogenase [19]. The ethanol yields from hexose fermentation could reach up to $90 \%$. Hence, this yeast was chosen for fermenting of the elephant grass hydrolysates.

As the OD value increased and the amount of substrate decreased, the ethanol concentration produced was also enhanced. It can be seen in Figure 8 that the optimum ethanol concentration obtained at the 48 th hour is $5.26 \mathrm{~g} / \mathrm{L}$ for the $5 \%$ inoculum concentration and $10.79 \mathrm{~g} / \mathrm{L}$ for the $10 \%$ inoculum concentration. However, the concentration was decreased after the first hour. However, the concentration was decreased after 72 and 96 hours of fermentation process. This can be caused by the amount of substrate that has been significantly reduced and microorganisms that have begun to change into the phase of death that supported by ethanol to renew or oxidize into another product, namely, acetic acid. In contrast to the inoculum concentration of $20 \%$, which at the beginning of the fermentation, the product also produced acetic acid, which reached up to $2.28 \mathrm{~g} / \mathrm{L}$, while ethanol was not detected. However, in the 48th hour, the concentration of acetic acid decreased, but the ethanol concentration increased. When viewed from the OD value, it can be said that the microbes are still in the stationary phase or the number of dead and living microbes were balanced; therefore, the fermentation could still be continued longer, because at the beginning of fermentation, only xylose was optimally converted while the remaining glucose levels are still high, i.e., $9.93 \mathrm{~g} / \mathrm{L}$. It was found that the optimum ethanol concentration obtained at the 96th hour was $13.31 \mathrm{~g} / \mathrm{L}$, while the concentration of acetic acid decreased. Therefore, the fermentation process can be continued with a longer time, so that more ethanol products were formed.

One of the major challenges in bioethanol production is the fermentation of xylose. Intensive efforts have been conducted to introduce organisms that can use xylose to produce ethanol. Hence, in this study, we used $P$. stipitis to covert pentose sugars such as xylose and produced ethanol by the pentose phosphate pathway. Yadav et al. reported that the optimal temperature was $27-30^{\circ} \mathrm{C}$ and the $\mathrm{pH}$ was about 3.0-5.5 [11]. Furthermore, P. stipitis was able to convert xylose to ethanol anaerobically or moderately anaerobically with high yields, for example, $0.3-0.44 \mathrm{~g}$ of ethanol $/ \mathrm{g}$ of xylose at $30^{\circ} \mathrm{C}[20]$. Therefore, this yeast combined with S. cerevisiae was used as the microorganisms to ferment the hydrolysates of elephant grass to produce bioethanol.

Ethanol yield $\left(Y_{\mathrm{p} / \mathrm{s}}\right)$ in the elephant grass hydrolysate fermentation process, as shown in Table 5, is directly proportional to the rate of productivity (Lp) and fermentation efficiency (EF). The optimum results were achieved when fermentation occurred at 48 hours, which reached up to 23.15\%; however, there was a decrease at 72 hours and 96 hours. This decrease is due to the presence of other secondary products, and one of them is acetic acid, as evidenced in Figure 8, which results in a decrease in ethanol production as the concentration of acetic acid increased at 72 and 96 hours.

A previous study on bioethanol production from rice straw hydrolysates using coculture of $S$. cerevisiae and $P$. stipitis achieved bioethanol concentration of $12 \mathrm{~g} / \mathrm{L}$, with a productivity value of $0.33 \mathrm{~g} / \mathrm{L} / \mathrm{d}$ and fermentation efficiency of up to $95 \%$ [11]. Kosasih also reported that bioethanol concentration obtained from empty palm bunch hydrolysates by using $S$. cerevisiae-P. stipitis and $S$. cerevisiae -Kluyveromyces marxianus was $9.67 \%$, with a productivity rate of $0.08 \mathrm{~g} / \mathrm{L} / \mathrm{d}$ [21]. In the present study, the highest bioethanol concentration achieved was $13.31 \mathrm{~g} / \mathrm{L}$, on day 96 , by using the $20 \%(\mathrm{v} / \mathrm{v})$ inoculum concentration.

\section{Conclusion}

In this study, the biomass content after alkaline delignification using the microwave-assisted acid hydrolysis technique was $47.4 \%$ of cellulose, $24.3 \%$ of hemicellulose, $10.8 \%$ of lignin, and $10.7 \%$ of ash, at the following optimal conditions: concentration of $\mathrm{H}_{2} \mathrm{SO}_{4}, 2 \%$; temperature, $95^{\circ} \mathrm{C}$; microwave irradiation power, $400 \mathrm{~W}$; hydrolysis time, $30 \mathrm{~min}$. The reducing sugar content was $26.63 \mathrm{~g} / \mathrm{L}$, indicating the hydrolysis efficiency of $66.57 \%$. Sugar levels elevated by $45.05 \%$ compared to the unassisted microwave irradiation process. The optimal time for the growth of S. cerevisiae ITBR89 and P. stipitis ITB-R58 was at hours 48 and 60, respectively. To investigate the optimal sugar mixtures of hydrolysis products (fructose and xylose), which are subsequently converted into bioethanol by cofermentation, the concentration of the inoculum was varied for 5 days ( $48 \mathrm{~h})$ at a temperature of $30^{\circ} \mathrm{C}$ and $\mathrm{pH}$ of 4.5 . The HPLC analysis revealed that $10 \%(\mathrm{v} / \mathrm{v})$ inoculum concentration was the optimal concentration for converting $76.15 \%$ of sugar mixture substrate (glucose and xylose) into $10.79 \mathrm{~g} / \mathrm{L}$ (34.74\% yield) of bioethanol, and the optimal rate of ethanol productivity of $0.45 \mathrm{~g} / \mathrm{L} / \mathrm{d}$ corresponded to a $69.48 \%$ fermentation efficiency.

\section{Data Availability}

The data used to support the findings of this study are available from the corresponding author upon request. 


\section{Conflicts of Interest}

The authors declare no potential conflicts of interest with respect to the research, authorship, and/or publication of this article.

\section{Acknowledgments}

The authors present the best gratitude to the Timor University and Bandung Institute of Technology for facilitating this research.

\section{References}

[1] N. Saifuddin and R. Hussain, "Microwave assisted bioethanol production from sago starch by co-culturing of ragi tapai and Saccharomyces cerevisiae," Journal of Mathematics and Statistics, vol. 7, no. 3, pp. 198-206, 2011.

[2] S. V. Vassilev, D. Baxter, L. K. Andersen, C. G. Vassileva, and T. J. Morgan, "An overview of the organic and inorganic phase composition of biomass," Fuel, vol. 94, pp. 1-33, 2012.

[3] C. Eliana, R. Jorge, P. Juan, and R. Luis, "Effects of the pretreatment method on enzymatic hydrolysis and ethanol fermentability of the cellulosic fraction from elephant grass," Fuel, vol. 118, pp. 41-47, 2014.

[4] H. Wang, M. L. Maxim, G. Gurau, and R. D. Rogers, "Microwave-assisted dissolution and delignification of wood in 1ethyl-3-methylimidazolium acetate," Bioresource Technology, vol. 136, pp. 739-742, 2013.

[5] W.-H. Chen, S.-C. Ye, and H.-K. Sheen, "Hydrolysis characteristics of sugarcane bagasse pretreated by dilute acid solution in a microwave irradiation environment," Applied Energy, vol. 93, pp. 237-244, 2012.

[6] H. Rouhollah, N. Iraj, E. Giti, and A. \&Sorah, "Mixed sugar fermentation by Pichia stipitis, Saccharomyces cerevisiae, and an isolated xylose fermenting kluyveromycesmarxianusand their cocultures," African Journal of Biotechnology, vol. 6, pp. 1110-1114, 2007.

[7] I. W. Arnata, "Alternative development of bioprocess technology in bioethanol production from cassava using trichodermaviride, Aspergillus Niger and Saccharomyces cerevisiae," Master thesis, Institute of Bogor Agriculture, Bogor, Indonesia, 2009.

[8] S. K. De Datta, Principles and Practices of Rice Production, John Wiley \& Sons, Hoboken, NJ, USA, 1981.

[9] P. Kumar, D. M. Barrett, M. J. Delwiche, and P. Stroeve, "Methods for pretreatment of lignocellulosic biomass for efficient hydrolysis and biofuel production," Industrial \& Engineering Chemistry Research, vol. 48, no. 8, pp. 3713-3729, 2009.

[10] K. S. Yadav, S. Naseeruddin, G. S. Prashanthi, L. Sateesh, and L. V. Rao, "Bioethanol fermentation of concentrated rice straw hydrolysate using Co-culture of Saccharomyces cerevisiae and Pichia stipitis," Bioresource Technology, vol. 102, pp. 6473-6478, 2010.

[11] N. K. Sari, "Making bioethanol from elephant grass by batch distillation," Jurnal Teknik Kimia Indonesia, vol. 8, pp. 94-103, 2010.

[12] T. Björling and B. Lindman, "Evaluation of xylose-fermenting yeasts for ethanol production from spent sulfite liquor," Enzyme and Microbial Technology, vol. 11, no. 4, pp. 240-246, 1989.
[13] T. W. Jeffries and Y.-S. Jin, "Metabolic engineering for improved fermentation of pentoses by yeasts," Applied Microbiology and Biotechnology, vol. 63, no. 5, pp. 495-509, 2004.

[14] M. J. Taherzadeh and K. Karimi, "Enzyme-based hydrolysis processes for ethanol from lignocellulosic materials: a review," Bioresources, vol. 2, pp. 707-738, 2007.

[15] N. W. Y. Ho, Z. Chen, and A. P. Brainard, "Genetically engineered Saccharomyces yeast capable of effective cofermentation of glucose and xylose," Applied and Environmental Microbiology, vol. 64, no. 5, pp. 1852-1859, 1998.

[16] Q. Xiang, Y. Y. Lee, P. O. Pettersson, and R. W. Torget, "Heterogeneous aspects of acid hydrolysis of $\alpha$-cellulose," Biotechnology for Fuels and Chemicals, vol. 107, no. 1-3, pp. 505-514, 2003.

[17] J. N. Nigam, "Ethanol production from hardwood spent sulfite liquor using an adapted strain of Pichia stipitis," Journal of Industrial Microbiology and Biotechnology, vol. 26, no. 3, pp. 145-150, 2001.

[18] K. Karhumaa, B. Wiedemann, B. Hahn-Hägerdal, E. Boles, and M.-F. Gorwa-Grauslund, "Co-utilization of L-arabinose and D-xylose by laboratory and industrial Saccharomyces cerevisiae strains," Microbial Cell Factories, vol. 5, no. 1, p. 18, 2006.

[19] J. Zaldivar, A. Borges, and B. \&Johansson, "Fermentation performance and intracellular metabolite patterns in laboratory and industrial xylose-fermenting Saccharomyces cerevisiae," Applied Microbiology and Biotechnology, vol. 59, pp. 436-444, 2002.

[20] T.-Y. Lee, M.-D. Kim, K.-Y. Kim, K. Park, Y.-W. Ryu, and J.-H. Seo, "A parametric study on ethanol production from xylose by Pichia stipitis," Biotechnology and Bioprocess Engineering, vol. 5, no. 1, pp. 27-31, 2000.

[21] F. R. Kosasih, "Making bioethanol from elephant grass by batch distillation production of bioethanol from oil palm empty bunches hydrolyzate through cofermentation," Undergraduate thesis, Bandung Institute of Technology, Bandung, Indonesia, 2014. 